\title{
Learning environments' influence on students' learning experience in an Australian Faculty of Business and Economics
}

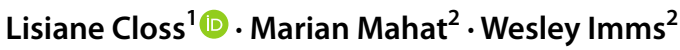

Received: 7 June 2020 / Accepted: 20 March 2021 / Published online: 29 March 2021

(c) The Author(s), under exclusive licence to Springer Nature B.V. 2021

\begin{abstract}
We investigated how learning environments-involving their physical, pedagogical, and psychosocial dimensions-influence students learning experiences in an Australian Faculty of Business and Economics. Qualitative data collection involved observations of eight classrooms over a semester, four focus groups with 21 students and interviews with six educators. The study provided deeper understanding of the dynamic and complex intrinsic interrelations of learning environment dimensions over time, addressing previous gaps in research. It identified and analysed spaces and practices, educational activities, and students' subjective experiences in different learning environments to illustrate how these multiple elements intersect and influence on the students' experience. The mixed methods used in the research helped to uncover a broader view of the learning environment and its interdependent influences over time on students' learning experiences. One practical implication is that any strategies to support a more holistic student learning experience through more effective use of learning environments should be developed at an institutional level.
\end{abstract}

Keywords Classrooms · Higher education · Learning environments · Student experience

\section{Introduction}

Higher education has been receiving growing attention worldwide in the literature resonating with its responsibility for preparing skilled people in the complex modern knowledge society (OECD 2019). Amongst learning needs reported in previous studies are nonroutine analytical and interpersonal skills, complex ways of thinking and doing (OECD 2019), flexibility, independence, responsibility, creativity, cooperation (Illeris 2009), self-directed learning and entrepreneurship (Fisher 2019). In particular, the recent financial, socio-environmental and health global crisis have fuelled the debate over the relevance of business

Lisiane Closs

lisiane.closs@ufrgs.br

1 Programa de Pós-Graduação em Administração, Universidade Federal do Rio Grande do Sul, Porto Alegre, RS, Brazil

2 Melbourne Graduate School of Education, The University of Melbourne, Melbourne, Australia 
schools and the importance of corporate social responsibility, ethics and leadership considering the positive and negative influences of organizations in society (Thomas and Cornuel 2011).

Although research should inform and help to improve educational practices, it does not seem to be supporting changes in higher-education teaching and learning (Acton 2018; OECD 2019). In relation to learning environments, most existing research focuses predominantly on their physical characteristics rather than on the alignment of spaces and practices, desired educational activities, behaviours, and student opinions (Acton 2018; Cleveland and Fisher 2014). There is a lack of holistic studies involving dynamic interactions and processes over time (Haggis 2009), particularly within classroom settings in higher education (Skordi and Fraser 2019), and their influence on students' learning experience (Chambliss and Taracs 2014; Tan et al. 2016). There is also a call for research into the interrelationship between the different dimensions of learning environments such as spaces, pedagogy, and learning (Acton 2018; McNeil and Borg 2018).

Based on the previous literature gaps identified, the research question that we addressed was: how do learning environments influence students learning experiences in higher education? Because learning is contextualised (Lave and Wenger 1991) in particular situations and places, this qualitative study was conducted in a single, large, renowned Australian university where international students represented 42\% of enrolments in 2018 according to the university website. The research involved the Faculty of Business and Economics which is located in a modern purpose-built building. This site was selected because of its potential to provide students with a favourable learning environment.

As the quality of university students' learning environments has been positively associated with student learning and experience at universities (Dorman 2014), our findings can support academics and educational managers to foster the development and improvement of higher-education learning environments.

\section{The dimensions of a learning environment}

Literature on learning environment research presents different concepts, understandings, and dimensions based on diverse epistemological and ontological perspectives. In this study, learning environment was conceived as the "social, physical, psychological, and pedagogical contexts in which learning occurs and which affect student achievement and attitudes" (Learning Environments Research 2019) and which allow an organic understanding of the students' learning experience in higher education. While elements such as financial resources, structure, people, and time are associated with organizational and government rules, processes or priorities might affect educators and students in the learning environments (Day 2009), their physical, pedagogical, and psychosocial dimensions play a central role in the learning process (Merriam and Brockett 2007).

\section{Physical dimension}

The physical dimension of a learning environment encompasses the physical structure, including technologies, tools, and furniture (Hannafin and Land 1997). The classroom physical space and its affordances-the learning activities allowed by furniture, technology, arrangement of rooms and so on-can stimulate or inhibit different teaching strategies (Beckers 2019; Marmot 2014). Research has also shown that colour, texture, views, light, 
acoustics, temperature and air quality are important elements of the physical learning environment (Marmot 2014), while aesthetic aspects are perceived as less relevant (Beckers 2019).

Millennial students need experiential and active learning spaces (Fisher 2019) which involve more participation and collaboration from students and require furniture that enables flexible classroom settings (Asino and Pulay 2019) where students can see and hear each other and their teacher, see all screens, and use suitable tables and chairs (Marmot 2014). In such spaces, teachers and students assume more agentive and active behaviour, relations of power are more balanced and fluid, and the teacher functions as a nucleus and students act as satellites in a dynamic way as the teacher moves around the room (Ravelli 2018).

The learning space signals to teachers and students to adopt a particular mode of teaching and learning and they tend to respond to the space consciously and subconsciously (Ramsay et al. 2017; Ravelli 2018). However, teachers can use new spaces in traditional lecture forms, on one hand, and lecture theatres in new innovative ways, on the other (Ravelli 2018). But, when the use of a familiar space deviates from previous experience, it often seems strange to students (Graetz 2006).

\section{Pedagogical dimension}

The pedagogical dimension of the learning environment (Skordi and Fraser 2019) relates to the activities, tools, resources, methods, strategies, and structures involved in facilitating student learning (Hannafin and Land 1997). Among the components that stand out in literature reviews on adult learning are: the voluntary nature of learning; self-directedness; the practical or experiential nature of learning; the collaborative and participatory nature of education; and the influence of self-concept on learning (Cranton 2006).

Contemporary learning environments are usually based on constructivist learning approaches and are student-centred. They encourage knowledge creation, consider the educator as a facilitator and coach, use cooperative work, adopt authentic assignments, and provide opportunities for self-regulated learning (Baeten et al. 2016; Stefanou et al. 2013). Although online quizzes and polling allow instant and faster feedback than was otherwise possible (Henderson et al. 2017), the massive use of digital technologies by students is mainly outcome-focussed, instead of having a more active, participatory or creative purpose (Henderson et al. 2017). Furthermore, tradition, national requirements, accreditation, teacher evaluation, and high-stakes testing restrict learning opportunities, and also can negatively influence students' learning experiences (Mishra et al. 2013).

\section{Psychosocial dimension}

Because the psychological and social dimensions are closely connected in a learning environment, these dimensions-aptly known as psychosocial-refer to the origins or outcomes of human behaviour. This dimension involves the ambiance or climate of a particular setting (Dorman 2014) and is a predictor of student affective and cognitive outcomes (Fraser 2012). Factors that characterise psychosocial environments include: personalization; involvement; student cohesiveness; satisfaction; task orientation; innovation; individualization; investigation; cooperation; equity; and teacher support (Dorman 2014; Skordi and Fraser 2019), and can also be categorised into the three general dimensions of relationship, personal development, and system maintenance and change (Moss 1974). 
The social aspects of the learning environment are increasingly acknowledged as central in the university student experience (Childers et al. 2014). Relationships with a friend, tutor or lecturer who cares can hinder or foster the motivation to learn and have a deep impact on student outcomes (Chamliss and Taracs 2014). Sharing of emotions between students and teachers (Merriam and Brockett 2007) also have been highlighted as positive aspects of a learning environment. Feelings of isolation, prejudice, and challenges in establishing relationships with domestic students, on the other hand, have been detrimental to students' learning experience, particularly for international students (Arkoudis et al. 2019).

Our study addressed all the previous learning environments dimensions simultaneously in order to deepen understanding of their influence on students learning experiences.

\section{The study}

This qualitative study used mixed methods-observations, focus groups and semi-structured interviews-to provide triangulation of data collected. The participants were students, lecturers and tutors involved in two undergraduate and one Master subjects.

\section{Observations}

Observations were conducted in eight different learning spaces: two large lecture theatres, one theatrette and five tutorial classrooms. Observations focused on the dynamic interactions and processes occurring in the learning environments over time (Haggis 2009; Skordi and Fraser 2019). One of the researchers observed the classes during a 12-week semester from August to October 2019. The physical, pedagogical and psychosocial aspects of the embodied learning environments observed-including verbal and non-verbal communication-were described in a field notebook (Thanen and Knights 2019).

\section{Focus groups}

Four focus groups involving 21 students were conducted by a single researcher following Liamputtong's (2011) procedures. Students self-selected voluntarily to participate in the study. Although student participation (see Table 1) was quite dispersed between the three subjects, there were almost equal numbers of undergraduate and graduate students as well as males and females, which provides a balanced perspective. Focus groups were

Table 1 Breakdown of numbers of student participants in focus groups

\begin{tabular}{|c|c|c|c|c|c|c|c|c|}
\hline \multirow[t]{3}{*}{ Group } & \multicolumn{4}{|c|}{ Undergraduate } & \multicolumn{4}{|c|}{ Postgraduate } \\
\hline & \multicolumn{2}{|c|}{ Domestic } & \multicolumn{2}{|c|}{ International } & \multicolumn{2}{|c|}{ Domestic } & \multicolumn{2}{|c|}{ International } \\
\hline & Male & Female & Male & Female & Male & Female & Male & Female \\
\hline Focus Group 1 (FG1) & 4 & - & - & - & - & - & - & - \\
\hline Focus Group 2 (FG2) & - & - & 2 & 1 & - & - & - & - \\
\hline Focus Group 3 (FG3) & 1 & 2 & - & 1 & - & - & - & - \\
\hline Focus Group 4 (FG4) & - & - & - & - & - & 2 & 1 & 4 \\
\hline Total & 5 & 2 & 2 & 2 & - & 2 & 4 & 4 \\
\hline
\end{tabular}


conducted in private comfortable rooms within the university campus right after the last day of the classes. Students were offered lunch or afternoon tea, depending on the time scheduled. The focus groups were audio-recorded and transcribed. Thematic analysis was performed involving initial and axial coding of data (Liamputtong 2011).

\section{Semi-structured interviews}

A single interviewer conducted semi-structured interviews with two tutors (T1 and T2), one tutor coordinator (TC), two undergraduate subject coordinators (SC1 and SC2), and a graduate subject coordinator (SC3). The face-to-face interviews integrated open questions in a pre-defined script based on the objective of the study and previous data. The audio-recorded interviews were transcribed and data were analysed using content analysis through an interpretive approach: printing, sorting, and then organising the data (Bardin 2011). The analysis was guided by the theoretical framework. Each author identified and grouped the findings into a priori established categories (learning environment dimensions) and into micro-categories that emerged a posteriori. The interpretations were compared, discussed, and then categorized. A semantic criterion was the basis of category constructions. Prior theory was used as a criterion in analysing and selecting the final categories presented in this article.

\section{Results: students' experience of learning environment}

We investigated various aspects of the students embodied experience in the learning environments. We have included the responses from focus groups and interviews that most accurately illustrate our findings, as well as aspects observed by the researchers. A synthesis of the overall research results is presented and discussed.

\section{Physical environment}

The undergraduate students in the study had classes in two lecture theatres and in five different tutorial rooms. The graduate students attended classes in a theatrette. The themes related to the learning environment dimension involved these specific spaces.

The lecture theatres had similar sizes (capacity for 502-506 students) and infrastructure: data projector, hearing aid loop, document camera, and lapel and lectern microphone for the lecturer (see Figs. 1 and 2). They were both generally perceived as modern and comfortable by undergraduate students participating in focus groups. The theatres were poorly illuminated to enhance the visibility of the screen(s). The comfort of the chairs and the temperature of the room had a sleepy effect on some students as observed by the researcher and illustrated in the following comment:

They turned the heaters on, and it's just more comfortable than with my bed at home... you can't help but fall asleep. (FG1)

These elements, reported as important in student learning (Marmot 2014), in addition to a non-engaging lecture, influenced students' embodied learning experience. By the middle of the lecture (around 20-25 min from its start), students would increasingly lean their heads on the back of the chair, yawn, or rub their eyes, among other physical 
Fig. 1 Lecture theatre for 506 students

Fig. 2 Lecture theatre for 502 students

signs of tiredness and disengagement in the class. Also, students would get distracted on their mobile devices when bored, as discussed in various focus groups and exemplified by a student quote:

I pick up my phone when I am really bored in a lecture or something. (FG2)

The size of the theatres, considered too big by students and lecturers, generated in students a sense of invisibility, also observed by Chambliss and Taracs (2014), that 'allowed' student behaviours illustrated by this comment:

We are spread out in this huge lecture theatre and everybody's just sitting in their own island and the lecturer is also kind of just wandering around not interacting so much... Everybody's looking at their computer [and], in my laptop, you can access so many things and people can't see what you're doing. So it's so easy to get distracted. (FG3) 
One lecturer (SC2) mentioned the difficulty in physically connecting with students apart from those in the first three or four first rows. Possibly associated with the lack of interaction and engagement, some students, especially domestic ones who lived far away from campus, claimed that they would not miss anything when not physically attending a lecture and therefore they watched its recording online at home (FG3).

Students were generally satisfied with their tutorial rooms according to the undergraduate focus-group discussions (FG1, FG2, FG3). Despite a few comments such as "being clinically like" or "not having an incredible look or colours" (FG3), the most important aspect for students was the functionality of the rooms (FG1; FG2; FG3) which corroborates Beckers' (2019) findings. White boards, large projector screens, chairs (and tables in one tutorial room) that can move, TV screens (in one tutorial) and good wi-fi connectivity were important affordances mentioned by students. These rooms provided a collaborative, interactive, and safe space which students enjoyed, therefore reinforcing millennials' preference for experiential and active learning spaces (Fisher 2019), as exemplified:

I enjoyed the tutorials a lot more than the lectures because it's a collaborative space where I feel a bit safer, I guess, to ask questions and get that immediate feedback.

When the questions were asked in the group, people would answer. (FG3)

Despite being considered a bit too small by one student (FG1), the best tutorial room for students according to T2 was tutorial room (A), shown in different angles and arrangements in Fig. 3. It had wide windows providing natural light, white boards on two walls, a computer and a projector (although students and the tutor presenting slides had to face the wall at the back of the room). It was the only tutorial room that had moveable tables and chairs. In this room, students organised the setting by joining tables before the tutorials started when they were not already in a group-work format, generating a sense of agency and active behaviour (Ravelli 2018). The room offered enough space for the tutor to move around and support students in class. This moving away from a focal point is characteristic in active learning spaces (Leonard et al. 2017; Ramsay et al. 2017). Students were close enough to work as a "whole class" (T2) which created a safe environment for students for participating, sharing knowledge, and hearing each other in class. The space also enabled students to write on boards and move around during exercises. This tutorial room provided sufficient flexible settings for experiential and active learning, and conditions for students to see and hear each other adequately (Asino and Pulay 2019; Marmot 2014).
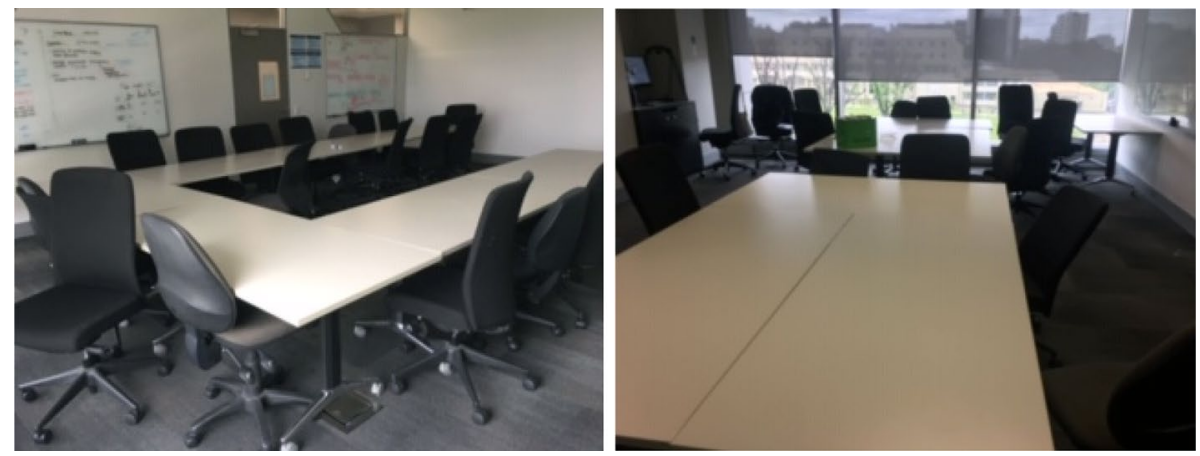

Fig. 3 Tutorial classroom (A) with different furniture arrangements 
The theatrette (Fig. 4), a smaller version of a lecture theatre, had a traditional configuration with rows of students facing the front (Marmot 2014; Thomas 2010). This space was "more about the teacher talking and the students at the receiving end" (SC3). The lecturer would like to have round tables so that students could look at each other and have a conversation instead of being in individual seats which don't allow it to happen.

In the focus groups, students shared feelings that their seats in the theatrette were "too tight, too narrow" and "hard to move" (FG4). On the other hand, compared with other bigger lecture theatres, students thought that the seating provided more intimacy and that everyone could hear the lecturer and other classmates adequately. Participants reinforced the millennial learners' preference for spaces that allow them to interact and collaborate (Asino and Pulay 2019; Fisher 2019). They also appreciated the comfortable chairs, the visibility of screens and the lecture recordings. The combination of colours, air quality and natural light had a positive influence on students' well-being, which is corroborated by Marmot's (2014) findings and illustrated by the following comment:

I like the combination of colours in the room... not very popped up, not very dull. So it is a quite good balance that keeps you calm [...] plus every lecture has windows.

So you know, it's not intoxicating. You feel the kind of air around always. (FG4)

Our findings show that not only the type of space (e.g. more or less student-centred) but also the combination of factors such as room sizes, furniture, and technology (un)reliability, influence students' learning experience.

\section{Pedagogical environment}

The most appreciated learning strategies observed by the researcher and expressed by students in the focus groups in general where the more hands-on, interactive, and collaborative ones, as identified in adult learning literature (Cranton 2006). Students valued being actively engaged in answering questions and "sharing experiences and knowledge" (FG4) with other students, which allowed them to learn from each other, especially in the graduate subject. In the Master subject, the role of facilitator adopted by the teacher (SC3) encouraged knowledge creation and cooperative work-key aspects in a student-centred learning environment (Baeten et al. 2016; Stefanou et al. 2013). Students also pointed out how discussions in class motivated them to be physically present instead of watching the lecture capture from home (FG4).
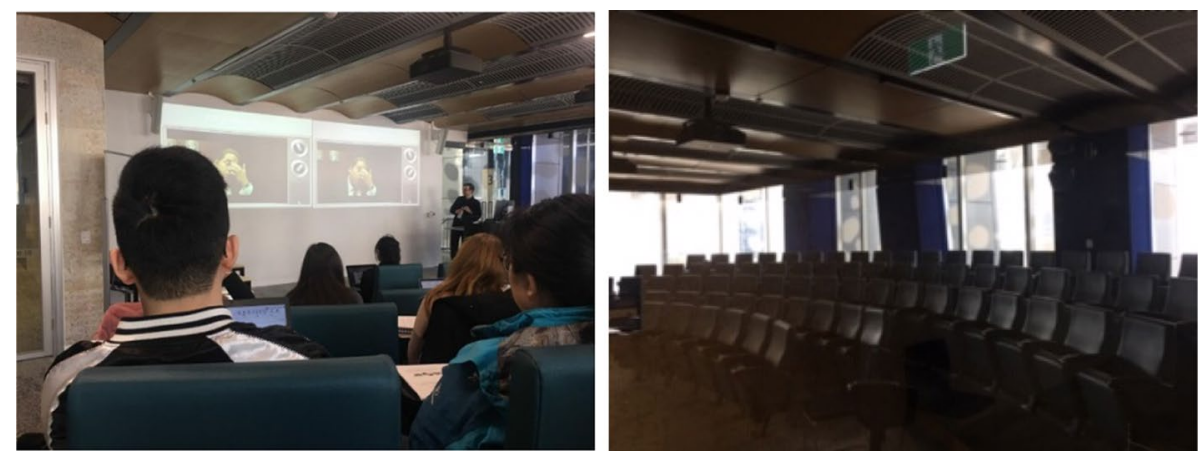

Fig. 4 Theatrette 
Undergraduate students preferred learning experiences that encompassed whole-body activities, as discussed in focus groups (FG1, FG2, FG3), such as working on case studies, writing an analysis on white boards, and rotating to read or add on classmates' work. The researchers also observed students' embodied joy in their gestures and movements, pointing proudly at their 'results', dancing, clapping and cheering each other's work. According to one student:

It's quite a physical activity; it's not just you on a laptop doing that. You go in and you write on boards, you know, you speak to people... I enjoy. It's different, you know, and I think it is better. (FG1)

Simulating a real-life production and supplying experience with Lego was another learning task that was appreciated by students and that "allowed things to come together" from theory to practice (FG2). Even though graduate students did not have this kind of experience in their subject, they also mentioned how meaningful it was for them to participate in experiential learning activities that they had in another subject (FG4), which corroborates previous higher-education literature (Baten et al. 2016; Stefanou et al. 2013).

Despite the criticism of the traditional lecture theatre delivery mode (Marmot 2014; Thomas 2010), a few strategies for breaking away from that mode were observed in the study. Asking students to discuss a question in pairs seemed to work well when students were already seated together as observed by the researcher. But when there were only around 80 students spread out in a 506-seat lecture theatre-which often happened - students who were isolated would not move their seats to share thoughts with a classmate. Trying to engage students leaving the 'stage' and walking around the theatre asking questions was not successful either because students felt embarrassed and threatened by answering in front of a huge audience (FG1, FG2) as exemplified in the following comment:

In lectures, it's very daunting. You don't want to make a fool of yourself if you get the answer wrong. So that's probably why everyone stays quiet, especially because it's recorded. (FG1)

Also, a non-traditional experiential learning activity involving a game of cards to connect theory and practice was perceived as one of the "awkward moments in the lectures" (FG1). This is consistent with the feeling of strangeness that students feel when the use of a space differs from their familiar experiences (Graetz 2006).

One engaging strategy for lectures mentioned by students in all focus groups was the use of online quizzes and polls. But students also pointed out some of its limitations, such as not having enough time to analyse questions and its excessive use (FG1, FG2, FG3). Additionally, technical issues were a consistent problem. Frequent failures experienced during the semester generated time pressure for lecturer SC2, as also found by Marmot (2014), and signs of impatience in students.

Another aspect mentioned by students was class time management (FG1, FG3, FG4). Students would lose interest when academics spent too much time introducing a class, explaining a concept already known, or allowing long discussions, and then had to rush with the theory at the end of the class. A student quote illustrates this:

When that's happening, I just sort of lose interest [...] I feel like he could have already delivered [the content] in a couple of minutes and very clearly, but it's just stretched out. I'm just like thinking what am I doing here exactly? (FG3)

Students would maintain their attention longer when academics, among other dynamic activities, walked around the room, asked questions, and presented 
attractive slides with limited content, videos, current cases, and examples relevant to the young and multicultural audience. This reinforces the importance of student-centred approaches (Baeten et al. 2016) and varied activities for students' learning experience, but it also underlines the short attention span that students verbally and physically demonstrated in the study.

Group assignment was a controversial topic that generated different learning experiences and feelings. Students discussed some tutors' unnecessary negative expectations set for group work as exemplified by a student quote:

[The tutor] kept saying that it was going to be so difficult to work in a group. There was so much emphasis on the fact that we would have conflict and like it will be so difficult. Like genuinely my group had no conflicts. (FG3)

Peer assessment as a way of punishing "free riders" in groups was also discussed. A typical question was "why should the person who hasn't worked get the marks for something that I have done for them?" (FG4). When planned as a video assignment with tasks that required students to work as a team, though, it contributed to team building and communication skills, providing an appreciated learning experience as exemplified by the following comment:

I like the communication aspect because you get to hear from other people [...] You get to understand how they think, and you learn from other people. (FG1)

Despite the benefits of the cooperative work (Baeten et al. 2016; Stefanou et al. 2013) offered by group assignments, managing them was one of the most-difficult challenges mentioned by teachers (T1, T2, TC, SC3).

Another salient aspect observed in the study was concern about examinations. Academics mentioned that subjects were often more geared to examinations than to learning outcomes, even though it was not considered the best way to assess students learning (SC2, $\mathrm{SC} 3, \mathrm{~T} 1)$. While examinations are required as part of course accreditation and/or universities policies (Mishra et al. 2013), too much emphasis seems to have been placed on them. Particularly for international students-for whom English is not their first language-a time limit to answer questions is a hurdle and 'closed book' examinations were difficult and caused pressure and fear, which might decrease students' cognitive capabilities (FG4). Examinations also stimulated rote learning and the pursuit of "right answers" (FG1, FG2, FG3, FG4, SC2, T2), which does not foster the critical and creative thinking (Marmot 2014) demanded by modern society (OECD 2019).

Students also valued well-structured subjects with clear plans, assignments, rubrics, assessments, applicable knowledge, and organized online learning management system (FG1, FG2, FG3) - aspects involved in effective higher education teaching (Ramsden 2003). Receiving assignments in advance allowed some students to work autonomously (FG1). Students also appreciated different kinds of assessments (individual and in groups) (FG1, FG3, FG4) because they enable testing of different skills and support different learning styles (Cranton 2006). Graduate students shared a negative perception about the overload of concepts and contents, which might limit their curiosity and pursuit of their own interests (Marmot 2014). But starting every class by recapitulating the last one and providing images synthesising ideas into a single slide were beneficial for their learning (FG4).

In all focus groups, students emphasised how important the support and solutions provided by academics were when they had difficulties with learning the subject matter, with classmates in group assignments, or specific personal and professional issues. The following quote exemplifies how academics handled such unique situations: 
The group issue just came in week 10. And everyone was crying, they were not talking to each other, and it sort of was just a different moment for me. And then I had to look at their assignments individually and write detailed feedback. (SC3)

To express this distinguishing aspect in their learning experience, we borrow from Van Manen (1991) the concept of pedagogical tact which requires an academic "to see a situation calling for sensitivity, to understand the meaning of what is seen, to sense the significance of the situation, to know how and what to do, and to actually do something right" (p. 146). It requires empathy and sensibility to support real-time understanding of students and take pedagogically-tactful action accordingly (Van Manen 2015).

\section{Psychosocial environment}

Closely related to pedagogical tact is the perception that academics care about students and want them to succeed in the subject that emerged; this was perceived as a very significant element for students' learning experience (FG1, FG2, FG3, FG4) which involves the relationship dimension of the learning environment (Moos 1974). Most students were concerned about giving the 'wrong answers', with the ability of educators to deal with that being crucial for maintaining students' participation in class. Thus, teacher support (Fraser et al. 1996), especially from tutors who teach in smaller groups and can get closer to students, was key in establishing a safe learning environment. This result corroborates with Chambliss and Taracs' (2014) findings regarding the influence of caring relationships on students' motivation to learn:

You're so much more willing to participate if you can tell they [teachers] care about your learning and want you to succeed [...] they're really encouraging, they don't say no, that's wrong. They offer an alternative, an example. [...] It's a nurturing environment. It depends a lot on the tutors. (FG1)

Students in all focus groups expressed their satisfaction when teachers called them by their names. Such findings corroborate elements involved in the personalisation scale, which is related to concern about students' personal welfare (Fraser et al. 1996). Respecting the identity of students with non-English names was another relevant aspect, particularly in the multicultural context of the study. After realising that students could give her a name that she could pronounce, Tutor 2 , for example, reported that she would tell her students:

You don't have to give me an English name that you don't really identify with to make it easier for me... If your original name is what you're comfortable with, stick with that. (T2)

Some language and communication barriers presented interaction challenges for students from different nationalities. International students from the same country tended to sit together in class and speak in their own language when it was over. These behaviours might result in difficulties for international students in improving their English fluency and in establishing relationships with domestic students. Common quotes from international students were: "It is not that easy [to make local friends] (FG3) and "Most of my friends are international students" (FG2). Domestic students also faced problems related to group work with international students as exemplified by the following comment: 
My group has had a little bit of difficulty and some people don't really understand. [...] I just feel like we're not on the same level and I'm not sure if it's a communication thing because of language or if it's communication thing because they are just personally not good at communicating. (FG4)

In order to promote student cohesiveness (Skordi and Fraser 2019), one subject coordinator used a template in the graduate subject to organize students in cultural, gender, work experience, and other diversity criteria. This enabled students to get to know each other and was appreciated by students. According to the lecturer:

That kind of package has worked for us where we've asked for diversity. [...] I think that template is a star. It's one of the best things ever in this class. And I think that also lets students share with each other. That came out in the reports as well. (SC3)

Another subtle aspect influencing the psychosocial learning environment was associated with student gender and ethnicity. A group of domestic white male students, for example, had a negative influence on other students' participation in one of the tutorials. Whispers, gazes, and laughs from this group generated a tense learning environment and mitigated the involvement (Fraser et al. 1996) of other students in class. Similar situations, detrimental to the classroom climate (Dorman 2014), arose in other classes according to tutors to present difficult challenges to overcome (when they could) in order to build trust and students cohesiveness in class (Dorman 2014; Skordi and Fraser 2019). Another situation that illustrated these aspects occurred in a tutorial during a hands-on activity when the researcher observed a female Asian student trying to participate in an exercise with a group of domestic male Caucasian students, but was 'invisible' to them. Such invisibility was equally noticed by an academic:

Some Asian girls were probably sitting right in front of me and I completely ignored them in the class, not intentionally, but it just apparently happened to be that they weren't vocal. So, in a class that is so noisy and talkative, sometimes a lot of people get missed out. (SC3)

Although perceived by the researcher during observations, such situations were silenced by students in the focus groups. Previous research, though, has reported how Australian higher education permits men to dominate discussion, as well as physical and discursive spaces (Gray and Nicholas 2019). Such aspects of the psychosocial learning environment, involving teacher support and student interaction and learning from each other, were among the most salient in the students' learning experience in this study, corroborating previous research (Chamliss and Tarac 2014; Childers et al. 2014).

\section{Discussion}

Our results shed light on how physical, pedagogical, and psychosocial dimensions of the learning environment are closely interconnected and have an impact on the students' learning experiences. Specifically, physical spaces facilitated or hindered different pedagogies and influenced the psychosocial learning environment. Flexible spaces, such as tutorials classrooms, for example, supported students and teachers in agentive and active behaviours (Ravelli 2018), cooperative work, and knowledge creation. Such a student-centred physical and pedagogical learning environment dimensions (Baeten et al. 2016; Stefanou et al. 2013) stimulated student cohesiveness and satisfaction-elements from the psychosocial 
dimension (Dorman 2014; Skordi and Fraser 2019) which all influenced the students' learning experience.

On the other hand, teachers have shown that more-interactive and collaborative pedagogies (Ravelli 2018) could engage students in higher-order learning (French et al. 2019) even in more traditional teacher-centred classrooms such as the theatrette classroom. The pedagogy adopted motivated students to be physically present in class, providing more personalization, involvement, cooperation, equity, and satisfaction, influencing the psychosocial learning environment (Dorman 2014; Skordi and Fraser 2019) and the overall student learning experience. Furthermore, pedagogical tact, subject organisation, amount of content, time management, assignment planning, and an excessive focus on assessments by the university all influenced the psychosocial dimension of the students learning environment.

Results for the psychosocial dimension also call attention to the interrelated influence of learning environment dimensions on one another. Teacher support, for example, would stimulate willingness to participate in class and interfere with the pedagogical dimension. Additionally, the mix of national and international students in a class would interfere with different uses of the classroom spaces.

The importance of the psychosocial learning environment dimension elements such as sharing emotions between students and teachers (Merriam and Brockett 2007), and supportive relationships (Chambliss and Taracs 2014; Childers et al. 2014), especially teachers' influence on this, have been previously discussed in the literature. The role of students, however, has gained less attention. This study illuminates how students' nationalities, genders, and ethnicities influenced different uses of spaces in the classroom physical environment, as well as the effectiveness (or not) of the learning activities proposed by tutors and lecturers. Being aware of cultural differences and learning how to treat students equally (Skordi and Fraser 2019), helping to avoid isolation and prejudice, and supporting diverse relationships are relevant elements in improving the quality of students' learning experience (Arkoudis et al. 2019), but they still represent a challenge for educators and universities.

The massive use of technology by students and teachers has been mainly outcomesfocused and does not seem to support more participatory or creative activities, as observed by Henderson et al. (2017). Technology should be able to recreate learning "spaces" that allow the interaction and collaboration required by students (Asino and Pulay 2019; Fisher 2019). Furthermore, the short attention span of students, incentivized by the immediatism that information and communication technologies generate, might highlight a need to emphasize in education the importance of stopping, analysing, and reflecting before giving immediate responses to the ever more complex solutions to the problems that the world is facing (Coll and Monereo 2010).

\section{Conclusion}

In this study, we sought understanding of how learning environments-involving physical, pedagogical, and psychosocial dimensions-influence students' learning experiences in an Australian Faculty of Business and Economics. The study has deepened understanding of the dynamic and complex intrinsic interrelations of learning environment dimensions over time, addressing previous gaps in research (Acton 2018; Chambliss and Taracs 2014; Cleveland and Fisher 2014; Haggis 2009; Skordi and Fraser 2019). We also identified and analysed spaces and practices, educational activities, and students' 
subjective experiences in different learning environments to illustrate how these multiple elements intersect and influence students' experience. Also, the protocol of mixed methods used in the research contributed to uncovering a broader view of the learning environment and its interdependent influences over time on the students' learning experiences.

The importance of learning environments in higher education continues to gain momentum. One implication that is clear is that any strategies to support a more holistic student learning experience through more effective use of learning environments should be developed at an institutional level (Day 2009). Constraints, such as tight subject organisation and high-stakes examinations stimulate rote learning and anxiety, which are detrimental to the student learning experience (Mishra et al. 2013). Flexibility, independence, responsibility, creativity (Illeris 2009), and self-directed learning (Fisher 2019), among other skills demanded by modern society (OECD 2019), are equally hindered by those institutional powers. This discussion goes beyond learning environments, but considering the relevance of business schools for preparing socially-responsible and ethical organisational leaders for society (Thomas and Cornuel 2011), especially in face of the COVID-19 crisis, we highlight the relevance of this debate.

\section{References}

Acton, R. (2018). Innovating lecturing: spatial change and staff-student pedagogic relationships for learning. Journal of Learning Spaces, 7(1), 1-15.

Asino, T. I., \& Pulay, A. (2019). Student perceptions on the role of the classroom environment on computer supported collaborative learning. TechTrends, 63(2), 179-183. https://doi.org/10.1007/s11528-018-0353-y.

Arkoudis, S., Dollinger, M., Baik, C., \& Patience, A. (2019). International student's experience in Australian higher education: Can we do better? Higher Education, 77, 799-813. https://doi.org/10.1007/ s10734-018-0302-X.

Baeten, M., Kyndt, E., Struyven, K., \& Dochy, F. (2016). Student-centred learning environments: An investigation into student teachers' instructional preferences and approaches to learning. Learning Environments Research, 19(1), 43-62. https://doi.org/10.1016/j.edurev.2010.06.001.

Bardin, L. (2011). Content analysis. Edicoes.

Beckers, R. (2019). Learning space design in higher education. In K. Fisher (Ed.), The translational design of universities. (pp. 194-175). BrillSense. https://doi.org/10.1163/9789004391598_010.

Chambliss, D., \& Takacs, C. (2014). How college works. . Harvard University Press.

Childers, C., Williams, K., \& Kemp, E. (2014). Emotions in the classroom: Examining environmental factors and student satisfaction. Journal of Education for Business, 89(1), 7-12.

Cleveland, B., \& Fisher, K. (2014). The evaluation of physical learning environments: A critical review of the literature. Learning Environments Research, 17(1), 1-28. https://doi.org/10.1007/s10984-013-9149-3.

Coll, C., \& Monereo, C. (2010). Psicologia da Educação Virtual: Aprender e ensinar com as tecnologias da informação e da comunicação. Artmed.

Cranton, P. (2006). Fostering authentic relationships in the transformative classroom. New Directions for Adult and Continuing Education, 109, 5-13.

Day, K. (2009). Creating and sustaining effective learning environments. All Ireland Journal of Teaching and Learning in Higher Education, 1(1), 1-13.

Dorman, J. P. (2014). Classroom psychosocial environment and course experiences in pre-service teacher education courses at an Australian university. Studies in Higher Education, 39(1), 34-47. https://doi.org/10. 1080/03075079.2012.674936.

Fisher, K. (Ed.). (2019). The translational design of universities: An evidence-based approach to aligning pedagogy and learning environments. Sense Publishers.

Fraser, B. J. (2012). Classroom learning environments: Retrospect, context and prospect. In B. J. Fraser, K. G. Tobin, \& C. J. McRobbie (Eds.), The second international handbook of science education. (pp. 11911239). Dordrecht: Springer. https://doi.org/10.1007/978-1-4020-9041-7_79.

Fraser, B. J., Fisher, D. L., \& McRobbie, C. J. (1996). Development, validation, and use of personal and class forms of a new classroom environment instrument. Paper presented at the annual meeting of the American Educational Research Association, New York.

French, R., Imms, W., \& Mahat, M. (2019). Case studies on the transition from traditional classrooms to innovative learning environments: Emerging strategies for success. Improving Schools, 23(2), 175-189. 
Graetz, K. A. (2006). The psychology of learning environment. Educause Review, 41(6), 60-75.

Gray, E. M., \& Nicholas, L. (2019). 'You're actually the problem': Manifestations of populist masculinist anxieties in Australian higher education. British Journal of Sociology of Education, 40(2), 269-286. https://doi. org/10.1080/01425692.2018.1522242.

Hannafin, M., \& Land, S. M. (1997). The foundations and assumptions of technology-enhanced student-centered learning environments. Instructional Science, 25(1), 167-202.

Haggis, T. (2009). What have we been thinking of? A critical overview of 40 years of student learning research in higher education. Studies in Higher Education, 34(4), 377-390. https://doi.org/10.1080/0307507090 2771903.

Henderson, M., Selwyn, N., \& Aston, R. (2017). What works and why? Student perceptions of 'useful' digital technology in university teaching and learning. Studies in Higher Education, 42(8), 1567-1579.

Illeris, K. (2009). Transfer of learning in the learning society: How can the barriers between different learning spaces be surmounted, and how can the gap between learning inside and outside schools be bridged? International Journal of Lifelong Education, 28(2), 137-148. https://doi.org/10.1080/026013709027569 86.

Lave, J., \& Wenger, E. (1991). Learning in doing: Social, cognitive, and computational perspectives. . Legitimate peripheral participation. Cambridge University Press. https://doi.org/10.1017/CBO9780511815355.

Liamputtong, P. (2011). Focus group methodology: Principles and practice. . SAGE.

Leonard, S., Fitzgerald, R., Bacon, M., \& Munnerley, D. (2017). Mapping next generation learning spaces as a designed quality enhancement process. Quality in Higher Education, 23(2), 168-182. https://doi.org/10. 1080/13538322.2017.1358955.

Marmot, A. (2014). Managing the campus Facility management and design, the student experience and university effectiveness. In P. Temple (Ed.), The physical university: Contours of space and place in higher education. Routledge.

McNeil, J., \& Borg, M. (2018). Learning spaces and pedagogy: Towards the development of a shared understanding. Innovations in Education and Teaching International, 55(2), 228-238.

Merriam, S. B., \& Brocket, R. G. (2007). The professional and practice of adult education: An introduction. . Jossey-Bass.

Mishra, P., Fahnoe, C., \& Henriksen, D. (2013). Creativity, self-directed learning and the architecture of technology rich environments. TechTrends, 57(1), 10-13.

Moss, R. H. (1974). The social climate scales: An overview. . Consulting Psychologists Press.

OECD. (2019). Trends shaping education 2019. . OECD Publishing.

Ramsden, P. (2003). Learning to teach in higher education. (2nd ed.). RoutledgeFalmer.

Ramsay, C., Guo, X., \& Pursel, B. (2017). Leveraging faculty reflective practice to understand active learning spaces: Flashbacks and re-captures. Journal of Learning Spaces, 6(3), 42-53.

Ravelli, L. (2018). Towards a social-semiotic topography of learning spaces: Tools to connect use, users, and meanings. In R.A. Ellis and P. Goodyear (Eds.), Spaces of teaching and learning: Integrating perspectives on teaching and research (pp. 63-80). Springer. https://www.springer.com/gp/book/9789811071546

Skordi, P., \& Fraser, B. (2019). Validity and use of the What Is Happening In this Class? (WIHIC) questionnaire in university business statistics classrooms. Learning Environments Research, 22(2), 275-295. https://doi. org/10.1007/s10984-018-09277-4.

Stefanou, C., Stolk, J., Prince, M., Chen, J., \& Lord, S. (2013). Self-regulation and autonomy in problem- and project-based learning environments. Active Learning in Higher Education, 14(2), 109-122. https://doi. org/10.1177/1469787413481132.

Tan, A. H. T., Muskat, B., \& Zehrer, A. (2016). A systematic review of quality student experience in higher education. International Journal of Quality and Service Sciences, 8(2), 209-228. https://doi.org/10.1108/ IJQSS-08-2015-0058.

Thanen, T., \& Knights, D. (2019). Embodied research methods. . Sage.

Thomas, H. (2010). Learning spaces, learning environments and the dis 'placement' of learning. British Journal of Educational Technology, 41(3), 502-511. https://doi.org/10.1111/j.1467-8535.2009.00974.x.

Thomas, H., \& Cornuel, E. (2011). Business school futures: evaluation and perspectives. Journal of Management Development, 30(5), 444-450. https://doi.org/10.1108/02621711111132957.

Van Manen, M. (1991). The tact of teaching: The measuring of pedagogical thoughtfulness. . State University of New York Press.

Van Manen, M. (2015). Pedagogical tact: Knowing what to do when you don't know what to do. Routledge.

Publisher's Note Springer Nature remains neutral with regard to jurisdictional claims in published maps and institutional affiliations. 